\title{
Choosing and Explaining Methods of Non- Destructive Control of Gear Mechanisms in Imported Excavators
}

\author{
Michael Drygin ${ }^{1 *}$, and Nikolai Kuryshkin ${ }^{1}$ \\ ${ }^{1}$ T. F. Gorbachev Kuzbass State Technical University, Department of informational and automated \\ production systems, 650000 Kemerovo, 28 Vesennya st., Russian Federation
}

\begin{abstract}
Kuzbass opencast coal mines use foreign produced excavators as basic equipment. Capital repair of these excavators involves complete replacement of all tooth wheel gearing in reduction gear boxes after 2 3 years of work (depending on operating time). The cost of this replacement is practically equal to the cost of new gear boxes. To minimize repair costs and extend service life of gear-tooth systems in gear boxes a methodology for monitoring technical state of gear boxes in imported mining equipment was developed. It allows to obtain reliable information about the level and significance of in-service defects in their elements. The research showed that the most reliable methods of control are visual and dimensional test $(67 \%)$ and fluorescent-magnetic inspection (32\%), and used together these two methods allow to detect up to $100 \%$ of significant defects. The most significant among service defects in typical elements of gearing systems are single and multiple cracks.
\end{abstract}

\section{Introduction}

More than $70 \%$ of coal in Russian Federation is mined by the open pit. The reason is that open cast coal mining is obviously more advantageous than underground. Kuznetsk Coal Basin is one of the largest in Russia and in the world [1-5].The main machines working at Kuzbass open cast coal mines are excavators, both produced in Russia (ESh, EKG), and imported (Komatsu, P\&H, Katerpillar). In recent years imported excavators are used more. Thus new Kuzbass open cast coal mines use dozens of times more imported excavators than those produced in Russia.

The majority of excavator units are repaired during its service time. Such basic units as engine, gear boxes, hydraulic motors, pumps, and hydraulic cylinders rarely end their performance potential more than 36000 motor hours, and their average performance potential is limited to $16000 \sim 24000$ motor hours. As a result in 5 years of operation all units are replaced and even more than once. This is explained by severe working conditions of the machines due to climatic and power factors [6].

Reducing gear boxes are the most important units in excavators. According to classic theory of mechanisms gear systems are higher kinematic pairs with the contact area of meeting surfaces theoretically equal to zero. High power transfer on these surfaces causes 
high stress which leads to their destruction. Similar processes occur in bearing supports of the shafts. Although replacing bearing units is not a problem that requires significant costs.

Using helical engagements in excavators would allow to increase the contact ratio 2 3 times. But the roller bearings in use cannot compensate axial components of the loads that appear. Sporadically using conic roller bearings complicates the structure and its maintenance requiring regular adjustment.

Using planetary gearing and closed rack-type differentials makes the situation slightly better. This allows to divide the power transferred into several flows by number of planetary gears and thus reduce the load on the gear pair and significantly downsize the mass-dimensional characteristics of the gear box [7].

\section{Formulation of the problem}

Gear system breakdown is a crucial problem because an excavator stops working if any of its reducing gear boxes goes out of order. This problem is aggravated by significant efforts during the repair, high costs of spare parts, and very often by absence of spare parts not only in authorized service centers, but even at manufacturing plants - spare parts are produced only by order in advance. On top of that, a breakdown of one unit leads to failures in others, and sometimes to the failure of the whole gear box. Therefore, trouble-free service of the gear box is one of the top priority tasks. For example, destruction of an output gear shaft (figure 1, a) in a swing gear of a Komatsu 750 excavator lead to full destruction of the hydraulic motor (figure 1, b) which caused 160 hours downtime and loss of 1.68 million rubles. Repair expenses and cost of spare parts reached 1.8 million rubles.

At the same time service centers are not interested in repairing and service life extension due to the policy of manufacturing plants that benefit by producing and delivering new spare parts, but not by extending service life of the old ones. Manufacturing plants present excessive rejecting norms. Thus for Komatsu excavators service life of a gear box is $2 \sim 3$ years. Then follows complete disassembly of the gear box and damage assessment with rejecting practically all gear sets and bearing units. This increases repair costs making them almost equal to the cost of a new gear box.

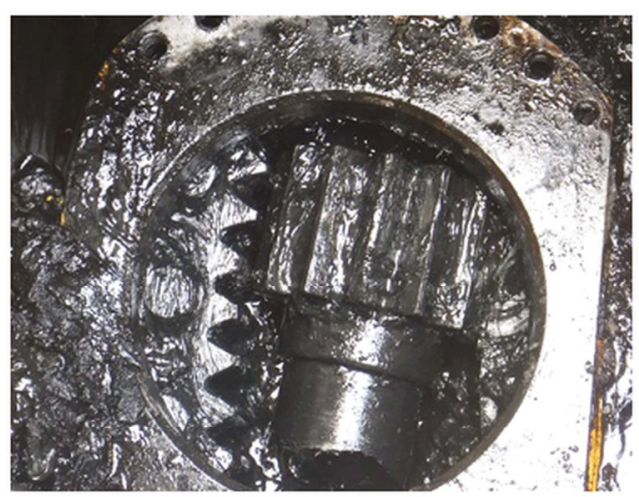

a)

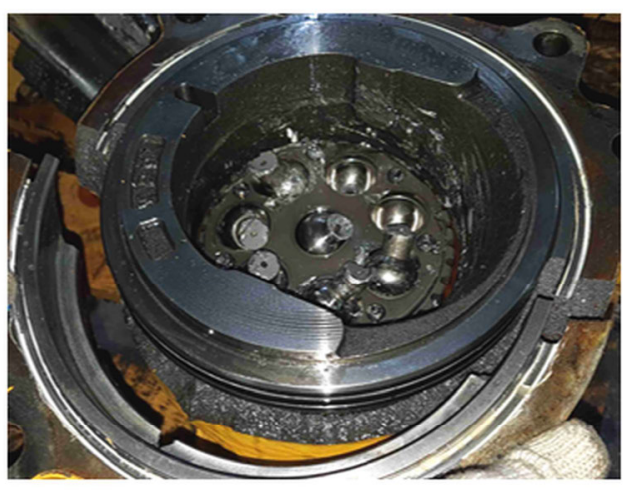

b)

Fig. 1. Damage of a reducing gear box in a Komatsu 750 excavator a) and its hydraulic motor b).

On the basis of the above information the main task of the research was defined: developing a methodology of monitoring technical state of gear boxes in imported mining equipment allowing to obtain reliable information about the significance of its elements' wear. 


\section{Theoretic}

Monitoring of the gear boxes' technical state is based on two approaches: operation control using vibration diagnostics by vibration parameters, and using various flaw detection methods to identify defective areas in metallic structures.

Although vibration diagnostics is a reliable method allowing to detect lots of flaws in gear boxes, it has a host of disadvantages. They are: inability to detect flaws that do not send any trouble signal (set in vibration) or send weak trouble signal both against the overall noise level, and in certain frequency ranges. For example a broken third of a tooth along its length is a very significant defect, but it does not provide any new vibration frequency components, therefore it cannot be identified by vibration diagnostics. The crack will show itself when its size becomes significant and allows the tooth bend and in a certain moment transfer the load on mating tooth. That will be a trouble signal.

The above mentioned defines the area of non-destructive test (NDT)for gear boxes. Thus it is reasonable to use vibration diagnostics for monitoring overall wear level, detection of the most significant flaws (broken teeth), and for monitoring the flaw of all bearing support structures and drive couplings.

Flaw detection methods make sense when the gear box is stopped (scheduled repair) and examined without disassembly (visual control using an endoscope), and during control procedures with partial disassembly and access through the inspection hatch within the scope of free access, or with complete disassembly and total control during capital repairs. In the latter case such flaw detection methods as visual and dimensional test (V\&DT), penetrant testing, magnetic particle test (MPT), eddy current test (ECT) are used.

Replacement of bearing units during the service time is not a significant problem, so this can be done either during minor maintenance works or big annual repairs. At the same time replacing all worn out gear systems becomes a very expensive task for the enterprise using the equipment, practically impossible to solve. The problem is aggravated by absence of new spare parts for multiple typical sizes of gear boxes in imported excavators.

All mentioned above makes obvious extension of worn out gear systems' service life. This will minimize operating and financial costs and consumed time due to extension of certain units' service life, and corrective actions allowing to withdraw from service those units that cannot be used because their further operation can cause destruction of adjacent devices or the whole drive mechanism.

A wide variety of non-destructive control methods gives an opportunity to detect flaws of any type in gear systems at the beginning stage with methodologically valid approach used. To detect those flaws the specialist carrying out control procedures must understand types of possible defects and physical processes causing them, adhere to the sequence of control procedures and apply methods necessary for the particular case.

Various standards and scientific literature present numerous variants of classifying gear systems' flaws, though it is impossible to apply them to heavy mining machines (excavators produced in Russia and imported, mining trucks like Belaz) without classifying the flaws and the level of their significance in case of this particular equipment. This requires developing a classification of flaws and identifying their significance.

At present time visual inspection is the only method of controlling gear systems' technical state used at mining enterprises. The procedure is usually carried out by specialists without necessary skills and equipment.

The most effective way to assess the degree of damage and validate the necessity of replacing toothed gear wheels is non-destructive teeth control. The procedure of nondestructive test can be carried out with complete disassembly and with partial disassembly through provided inspection hatches or with an endoscope. Figure 2 shows an element of a gear box (a carrier) prepared for a non-destructive test procedure. 


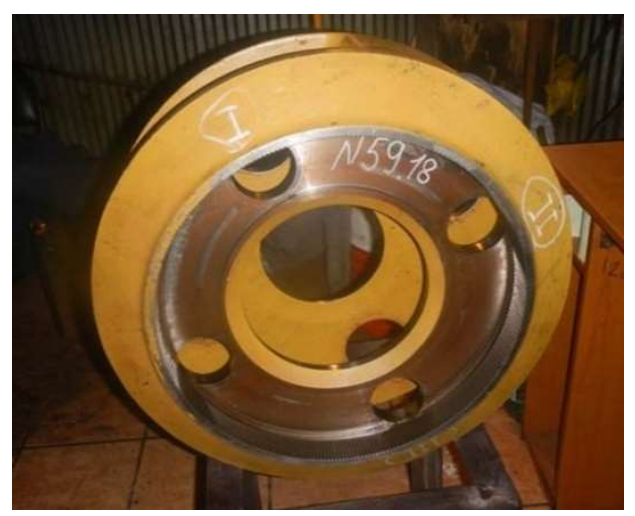

Fig. 2. Plain view of the carrier prepared for a non-destructive control procedure using visual and dimensional test method.

\section{Results and analysis}

Since April 2012 to September 2019, at one of Kuzbass open cast coal mines 57 items of planetary reductiongear boxes and slewing gears of Komatsu excavators were controlled. On top of that two sets of Komatsu PC1250 basic elements, one axle gear box of Komatsu GD825 grader, 41 Komatsu tooth rim, and 9 in-line raising gears of P\&H2300 excavators passed control procedures. Generally 810 elements underwent control: basic details, carriers, shafts, fine pitch gears $(\mathrm{m}<25 \mathrm{~mm})$, coarse pitch gears $(\mathrm{m} \geq 25 \mathrm{~mm})$.

Due to some technological characteristics of gear systems' non-destructive test gear shafts were presented for control procedures as two units and were assigned to different categories - shafts and gears. Thus all gear systems of the inspected planetary gear boxes - slewing gear rings, tooth-type couplings, sun gears, crown gears, satellite gears and other gears in slewing reducers and travel reducers as well as gear shafts of travel reducers - were classified as fine pitch gears. All gear systems of P\&H excavators, gears of vertically turning gear shafts (swinging shafts), and tooth rims of the swing bearing were classified as coarse pitch gears. Basic structures are gear box casings and covers.

Control procedures were carried out in two stages:

1. Visual inspection (by skilled and unskilled specialists) both in service and during planned current maintenance.

2. In laboratory and field conditions by skilled and qualified specialists using nondestructive methods of control.

Therefore, following the results of the first stage of visual control during a 36 month experiment no defects were found. This can be explained by specifics of manufacturing technology for imported details. Over a long period no significant or visible defects were observed. Then explosive fracture of a detail occurs. Besides that, gears with even minimal visually observed defects were rejected during the maintenance procedures preceding the control. Technical inspection and maintenance of the imported equipment is also traditionally characterized by more thorough approach.

The results of the second stage were more informative. Their quality in laboratory conditions was not different from the quality in the field conditions, but it was subject to high necessity of providing typical conditions for NDT. In the field conditions it required more efforts and increased by $120 \sim 150 \%$ subject to inconvenience of working process and a great number of organizational and preparatory procedure.

According to the control results flaw detected with different control methods were analyzed (figure 3). 
As it is shown on the bar chart the most efficient method is visual and dimensional test (V\&DT) (67\% of flaws detected). This method allowed to detect particularly such flaws as wreck, fracture, wear, mounting surface breach, burn-through, rust, cleavage, pitting, and $50 \%$ of casting flaws. On top of that V\&DT allows do detect flaws like single and multiple cracks if their breadth is enough for it.

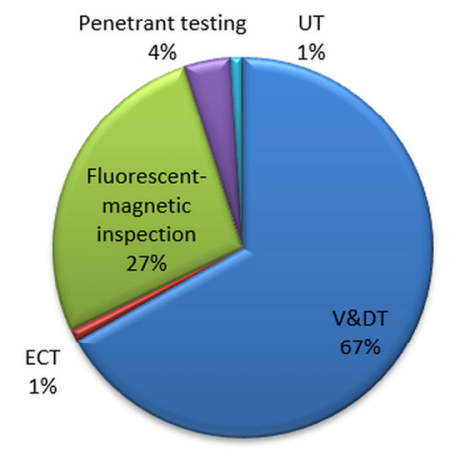

Fig. 3. Proportion of flaws detected with different control methods.

Methods like fluorescent-magnetic inspection and penetrating testing are used mainly to detect single and multiple cracks. Their part is respectively $27 \%$ and $4 \%$ from overall umber of flaws. In a single case (which makes $50 \%$ for such flaws) fluorescent-magnetic inspection detected a casting flow in the carrier of the slewing reducer. Dye penetrant inspection (penetrant test) also allowed to detect non-homogeneity of a deposited surface in a single case.

Ultrasonic testing (UT) method detects only internal unsoundness of shafts, therefore its efficacy makes only $1 \%$ of overall detected flaws. On top of that it detected only single nonhomogeneities that are work piece flaws irrelevant to service defects.

Eddy current method allowed to detect $1 \%$ of flaws $(11$ cracks $)$ that were confirmed by fluorescent-magnetic inspection.

Therefore, practically all flaws except single and multiple cracks are assigned to certain methods of control and do not need detail analysis. The situation with methods of detecting single and multiple cracks is specific. The vast majority of such flaws (68\%) was detected with fluorescent-magnetic inspection (figure 4).Visual and dimensional test is on the second place (21\%). Dye penetrant inspection (penetrant test) makes $9 \%$, and eddy current test makes $2 \%$. These flaws can be detected withfluorescent-magnetic inspection.

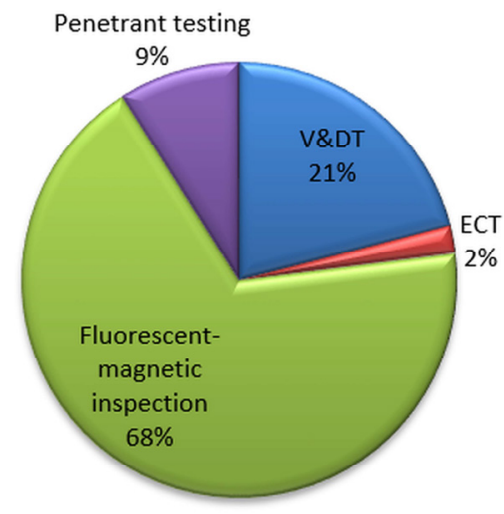

Fig. 4. Efficacy of different methods for detecting single and multiple cracks. 
According to delectability statistics for different types of flaw sin standard units (figure 5)visual and dimensional test is the most productive control method for all standard units, such as shafts, carriers, basic parts, fine pitch gears, and coarse pitch gears. The percentage of V\&DT efficacy for shafts is lower because ultrasonic control makes $30 \%$ of efficacy (it is explained by non-homogeneities registered by ultrasonic flaw detection in practically every shaft). Fluorescent-magnetic inspection is on the second place for carriers (28\%) and fine pitch gears (38\%). The efficacy of this method for shafts makes $20 \%$. The efficacy of dye penetrant inspection (penetrant testing) for coarse pitch gears makes $12 \%$, and only $9 \%$ the efficacy of fluorescent-magnetic inspection. All the rest values of control methods for certain standard units are insignificant.

The analysis of control methods efficacy for standard units (figure 6) showed that shafts, carriers, and fine pitch gears have similar structure of control methods during the flaw detection procedures. The majority of flaws $(84 \%, 96 \%$, and $94 \%$ respectively) was detected with fluorescent-magnetic inspection.

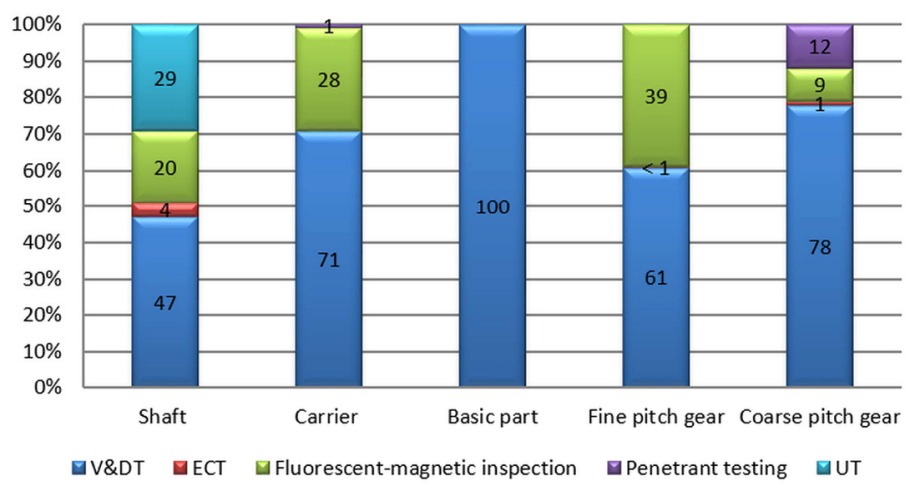

Fig. 5. Methods of flaw detection in typical units.

A small part of cracks in a shaft (16\%) was detected with eddy current method, $6 \%$ of cracks in fine pitch gears was detected with visual and dimensional testing.All the rest of the methods for the mentioned standard units are not significantly efficient.

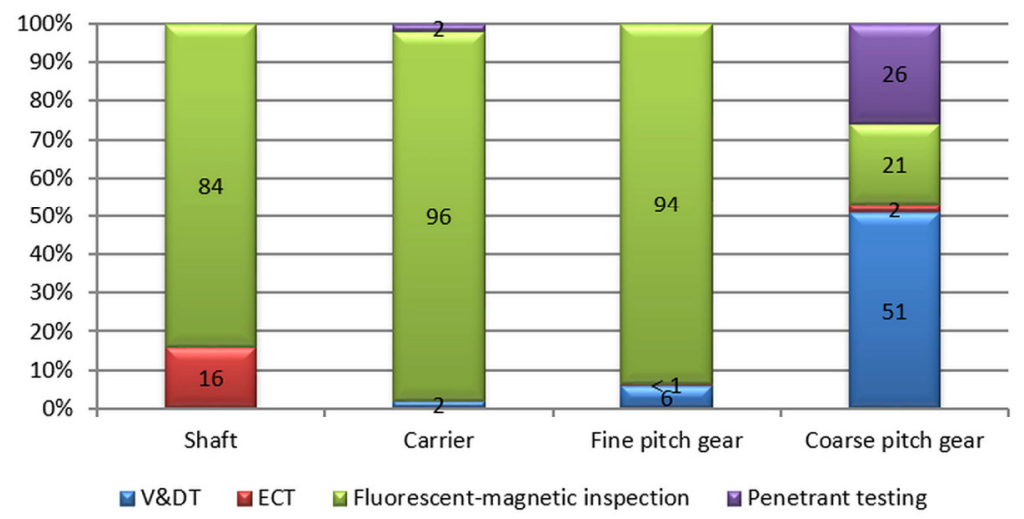

Fig. 6. Correlation of different methods of typical units control with single and multiple cracks.

The structure of control for a coarse pitch gear is different. The most efficient method here is visual and dimensional test (51\%).Dye penetrant inspection is on the second place $(26 \%)$.The efficacy of fluorescent-magnetic inspection makes only $26 \%$. Eddy current test in crack detection is efficient only in $2 \%$ of cases. 
This distribution of control methods can be explained by high sensitivity of fluorescentmagnetic inspection allowing to detect cracks even with minimal breadth, and such cracks are typical mainly for shafts, carriers, and fine pitch gears. Coarse pitch gears, particularly toothed rims, are characterized by broad and extended cracks that are easily detected with visual and dimensional testing or with dye penetrant inspection if necessary. This method allows to achieve higher efficiency of large sized units like coarse pitch gears which are extremely hard in magnetizing.

\section{Conclusion}

(1) New Kuzbass open cast coal mines use not only excavators manufactured in USSR and Russia, but also imported excavators. Technical regulations for repair of these excavators supposes practically compelete replacement of gear systems in reducing gear boxes in two or three years of service.

(2) A new methodology of technical state control for gear boxes in imported mining equipment was developed to minimize repair costs and extending gear systems' service life. This methodology allows to obtain valid information about the degree and significance of elements' wear.

(3) Industrial experiment carried out to detect service defects of 810 elements of reducing gear boxes in imported excavators showed that the most informative and reliable methods of non-destructive control are visual and dimensional test (67\%) and fluorescent-magnetic inspection (32\%). These methods allow to detect up to $100 \%$ of significant flaws when used together.

(4) The most significant service defects of standard units in gear systems are single and multiple cracks. Cracks in shafts, carriers and fine pitch gears $(\mathrm{m}<25 \mathrm{~mm})$ are most effectively detected with fluorescent-magnetic inspection $(84 \%, 96 \%$, and $94 \%$ respectively), and in coarse pitch gears $(\mathrm{m} \geq 25 \mathrm{~mm})$ - with visual and dimensional test (51\%)and with dye penetrant inspection (26\%).

\section{References}

1. H. Arden, A. Tverdov, Resource and Reserve Valuation Practices in CIS Countries. Mineral Resource and Ore Reserve Estimation. The AusIMM Guide to Good Practice (Nedra, Moscow, 2014)

2. V. Kovalev, A. Khoreshok, O. Litvin, The 8th Russian-Chinese symposium coal in the 21st century: mining, processing and safety, 1, 287-290 (2016)

3. A. Morshedlou, H. Dehghani, S. H. Hoseinie, JME, 5, 2 (2014)

4. M. Drygin, N. Kurychkin, A. Bakanov, E3S Web Conf. 15, 03011 (2017)

5. M. Drygin, N. Kuryshkin. JOP: Conf. Series, 944, 012030 (2018)

6. L. De Chiffre, S. Carmignato, R. Kruth, J. P. Schmitt, A. Weckenmann, Manuf. Technol., 63, 2 (2014)

7. E. Todorov, R. Spencer, M. Lozev, M. E., 72, 6 (2014) 